On attempting to pass the barrier, the ticket collector exclaimed to the Earl, who had the coat over his arm, "Holloa, where did you get that coat." The Earl was unaware that a ticket was attached to the coat, which had caught the inspector's attention, and caused him to look with suspicion upon the whole party. "Yes," said the Earl innocently, "there was no one in the cloak room, so I took it."

This was too much for the inspector, who, casting a glance at us, said in an authoritative tone, "Has anyone else boned a coat?"

"Come with me," said the Duke of Argyll to the Earl. "What does he mean by boned?"

"Stole it," says the Farl.

As we reached the cloak room the attendant, who had left it for a short time, was just entering the room, thus confirming the Earl's statement. Of course, this was quite satisfactory. "But," says Mr. Brearey, "I shall not easily forget $m y$ indignation at tho man's manner, nor my admiration at the suppression of any anger which must have been felt by the party. After they had departed, I could not avoid saying to the inspector, "Do you know who that gentleman was that you accused of stealing a coat?"

"I neither know nor care," said the man. carelessly.

"Well," I said, "he was the Earl of Dufferin, Governor-General of Canada; the taller of the two others was the Duke of Sutherland, and the other was the Duke of Argyll." so?"

"Good God!" said the man, "you don't say

With respect to the ultimate issue of the late plane propelled experiments, Mr. Brearey, who -at least, theoretically-became possessed of as much knowledge as anyone in this kingdom, said that there were two systems by which success has been ascertained to be certain, so far as ascent is securable by mechanical means alone, viz., Maxim's and Phillip's. The former answers to the prognostication of the Duke of Argyll, expressed when presiding over the first meeting of the Society in 1866.

"I think it quite certain that, if the air is ever to be navigated, it will not be by individual men flying; but that it is quite possible vessels may be invented which will carry a number of men, and the motive force of which will not be muscular action."

Mr. Maxim says that it is only for such dire purposes as war that his inventive genius has aimed at. This means heavy weights. Phillip's will come within the capacity of the pleasure seeker. Both have yet to come under control when set free in the air. Both inventors are members of the Society.

"Then," said Mr. Brearey, "will come the real test, and the real danger, but, that success will be ultimately attained, who that considers

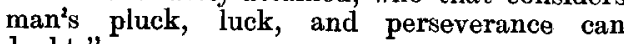
doubt."

On January 31st, 1896, Frederick William Brearey suddenly and peacefully passed away.

\section{The Death of Lilienthal.}

There can be no doubt that we learn as much from failures as from successes, and it is a pity that fruitless efforts are not more often put on record. How frequently it must occur in scientific investigations that a man works away upon some idea that occurs to him, when that same idea has occurred to hundreds of others before him who have also worked at it in the vain hope of attaining the desired end. A long register of failures may be uninteresting reading, but it may be very useful, especially when a full and clear reason is given for each failure. All students of aerial navigation have been interested in the accounts of the experiments of Herr Lilienthal, near Berlin. Everyone owned that, whether or not he was on the real road to the unravelling of the mysteries of flight, yet his experiences were of the greatest importance. He himself said, " this danger can only be avoided by becoming acquainted with the wind by constant and regular practice," and later, "I myself have made thousands of experiments within the las' 5 years, and have had no accidents whatever." It is very shocking, then, to hear one day that this bold experimenter was killed during one of his flights. He is bewailed as a martyr to science. People then asked "what happened?" and the answer is generally given that he lost his balance and fell, and there is an end of it. But this is not sufficient. It is most important for us to know how it was that Lilienthal, after all his practice and experience, came to grief. We will quote such accounts as have been published. The "Daily News" correspondent telegraphs: " $\mathrm{He}$ started with a machine from a hill about $100 \mathrm{ft}$. high, and at first all went well. After remaining in the air for a few minutes, however, the machinery got out of order, or according to another account, a sudden gust of wind caught the machine, and the unhappy man fell heavily to the ground." Now those who know this simple apparatus will ask what part of the "machinery" could get "out of order?" And as for the sudden gust of wind, it was just these gusts that the poor experimenter had been practising to combat for five years past. The next account we have reads: "Suddenly something went wrong with the machinery, the wings ceased to act, and he fell." Here again it is difficult to know how the wings, consisting of a rigid plane, could "cease to act." Another account says : "The apparatus lost its balance," and, "the details of the accident seem to show that the conduct of the parachute, for such it really was, was very nearly that predicted, for the machine turned several somersaults." Another commentator says:- "Any such apparatus which exposes large surfaces to the atmosphere is at the mercy of a sudden gust of wind, with the result that its equilibrium is destroyed, and the whole machine is overthrown and tumbles to earth." Now any careful experimenter knows that an apparatus can be made 
that will always be stable. Make a model of Lilienthal's machine, attach a heavy weight to it in the position of the man, and throw it about how you will in the air, it will always come down "cat-like" on its legs. No! we must look further afield to get at the real cause.

This machine, as is well known, consisted of an upper aeroplane, placed over the lower winglike structure around the man. A correspondent writing to "Nature" says: "These two-storey models soared in the most astonishing manner, . . and never showed the slightest tendency to take "headers." They "would also show a greater stability, a result all the more to be expected, as the centre of gravity of the system was placed more than a metre below the upper surface." This correspondent quotes the mechanic who, not unfortunately, was the only person to actually witness the disaster. "The man saw him soar down until he was nearly above the foot of the bill; then suddenly a gust of wind set in, lifted him up to a height of $30 \mathrm{~m}$. above the ground-according to his man's estimate-and then he stood apparently motionless in the air. This was a frequent occurrence, and gave no cause for alarm at first; but now the man saw how Lilienthal gradually lowered the fore-edge of his wings more and more, without obtaining the

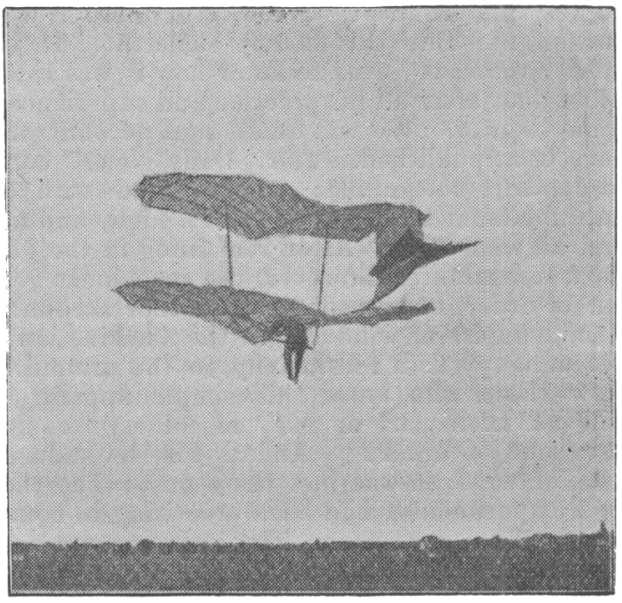

[From the Golden Penny

desired effect of getting way forward and downward. . . Suddenly he saw the apparatus heeling over forward still more, and then Lilienthal came down with it with great force, head foremost. When the man reached the spot he found the apparatus much shattered."

Though it is thus rather difficult to get at the exact account of this unfortunate occurrence, it is most probable that the machine tipped forward slowly and fell. But now, as has been said, a model of this two-storied plane will not act like this. On looking at a photograph of the apparatus, what at once strikes one is the extraordinarily delicate and flimsy connection there is between the two planes. Indeed, it is difficult to realize how the apparatus could be rigidly constructed. There are apparently two light upright rods connecting the aeroplanes; nothing more is visible, though presumably these are stayed with wire. But if extra pressure is brought on the front edge of the upper plane, what is to prevent its being forced back? Suppose for a moment it was forced back.

Would not the whole apparatus ut once pitch forward? The centre of gravity would come well in front of the centre of area, and nothing would prevent the machine taking a "header" to the ground, even, perhaps, making a somersault. The more one looks at the photographs, the more one wonders at the weak-looking connection of these aeroplanes, the more one sees how easily a slight mishap might cause the upper plane to shift back.

But there are other conjectures as to the cause of the accident. Mr. Pilcher, who has had great experience in England with an apparatus of very similar construction, remarked, on first hearing of Lilienthal's new double plane, that he did not like the looks of it, as he had found that if the man's weight was too far below the supporting surface, there was great difficulty in controlling and managing

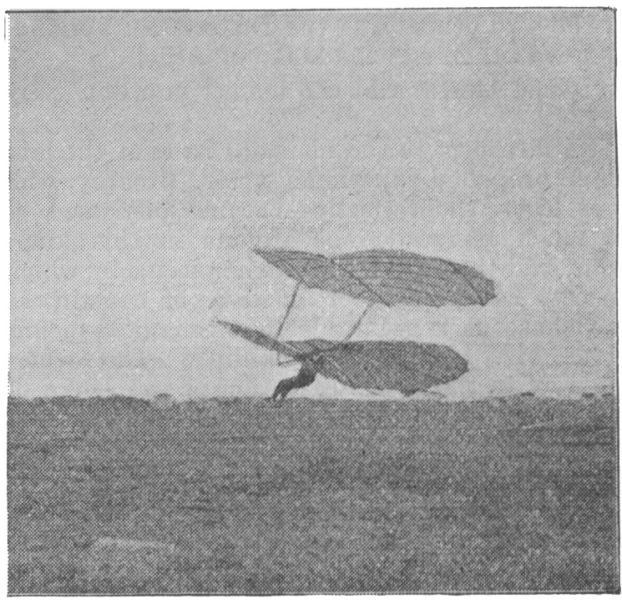

[From the Golden Penny.

the apparatus. There is also another cause, which is believed by those best acquainted with the circumstances, including Herr Lilienthal's brother, to account for the accident. In this fatal trial the inventor had adopted a method by which he could alter the position of the horizontal tail by a movement of his head. It is suggested that, not being practised with this appliance, he may have made some wrong movement of his head, which unexpectedly upset the balance. This certainly seems as if it might have been the cause of the accident, except that the eye-witness describes the 
pitching forward to have taken place slowly, and, if so, one would have expected the experimenter to have rectified his error in time.

Unfortunately the apparatus was completely smashed up, and beyond the fact that it was found lying upside down, gives no clue to the cause of the unfortunate mishap.

Captain Moedebeck, one of the best authorities in Germany, conjectures that in shifting the weight of his body, as he was accustomed to do, Lilienthal forgot about the apparatus connected to his head, and so counteracted the balance by the action of the tail.

Though we are, then, unable to account with certainty for the unfortunate mishap, we may at all events avoid in future accidents the causes of which are here suggested.

\section{Dr. Wolferts' Steerable Balloon.}

This elliptical-shaped balloon was shown in working order at the Berlin Industrial Exhibition last year, and was said to have acted very satisfactorily. It is provided with two screw propellers; one, about 9 feet diameter, placed in front of the car, is to propel the balloon horizontally, while another is placed underneath on a vertical axis to control the rise and fall. The engine is of 8 horse-power, giving 500 revolutions per minute to the propellers. The balloon is nearly $100 \mathrm{ft}$. long and $30 \mathrm{ft}$. through the centre.

\section{Speed of Flying Birds.}

To measure the exact velocity of birds in flight is no easy matter. Homing pigeons give a reliable record of the average rate of travel over long distances, but it may reasonably be presumed that this speed is not the maximum obtained, or even an average rate for steady flight, since the course would often not be in a straight line, and the speed affected by variable winds and other causes. Mr. S. P. Fergusson, however, made some careful measurements a short time since on a flock of ducks which happened to pass whilst he was engaged in measuring cloud velocities at the Blue Hill Meteorological Observatory. The result of these trigonometrical observations was that the birds were found to be moving at a height of $958 \mathrm{ft}$. above the ground, and that the velocity of their flight was 47.8 miles an hour. The wind at the time was light from the north, the direction of flight being from the north-east.

\section{Summary of News.}

Stentzet's Wing Machine. - A flying machine, similar in many respects to thase of the late Herr Lilienthal and Mr. Pilcher, has lately been experimented with at Altona, Germany. It possesses, however, one great point of difference from its predecessors in that the wings are pivoted so that they may be moved up and down as with those of a bird. The wings have a spread of about $21 \mathrm{ft}$., having a surface of about 76 square feet, and may be moved through an angle of $70 \mathrm{degs}$. The apparatus weighs 75 lbs. An engine, worked by compressed carbonic acid gas, is to be used for working the wings. It is stated that this engine, with a pressure of 5 atmospheres, is capable of producing 1 horse power, and that by increasing the pressure to seven or nine athospheres, the motor may be made to yield 2 or 3 horse power respectively. The wings, in shape, are not so round as those of Lilienthal, but are pointed towards the tips like a gull's. The tail or rudder consists of both horizontal and vertical planes.

Dr. Rroher's' MAchine.-It is announced that a large apparatus, chiefly consisting of two huge wings, is now being constructed in France. The inventor is Dr. Richet, a professor in the Faculty of Medicine at Toulon.

KITES Fon METEOROLOGY.-During last year a great deal has been done in America with regard to meteorological tests of the upper air by means of kites. Mr. Fergusson, of the Blue Hills Observatory, has written an interesting account in the "Monthly Weather Review" for September, of experiments conducted at that institution. The kites used were usually of the Malay pattern for light weather, and of the Hargrave type in strong winds. Self registering instruments were taken up by the kites, and some very great altitudes were attained, the highest being no less than $9,375 \mathrm{ft}$.

ANDREE's ARCTic BALLOON.-M. Andreé has stated that he intends making a fresh start this summer to explore the Arctic regions with his balloon. In addition to the continual adverse winds last year, he found that the balloon did not retain its gas quite so well as was expected, and doubtless before he starts again he will consider it necessary to add another covering, or, at all events, some fresh coats of varnish, to the envelope.

CHANUTE's ExPERIMENTs.-Although some sensational rumours have been published with regard to the trials of a flying machine on the shores of Lake Michigan, we have the best authority for stating that these have been simply some scientific experiments in gliding flight, which have so far produced no very important results. Mr. Chanute's name is a sufficient guarantee that they will be interesting from a scientific point of view, even though not intended to be a practical success. He has been assisted by Messrs. Paul and Herring.

\section{Recent Patents.}

THE following patents connected with Aeronautics were published during 1896 :- 